\title{
The Disposal and Experience of Unexpected Natural Disasters: a case of the 6.3 Earthquake in Puer
}

\author{
Ma Guofang \\ School of Public Administration, Yunnan University of Economics and Finance, \\ Kunming, P.R.China, 650221 \\ (E-mail: majinshu@yahoo.com.cn)
}

\begin{abstract}
Effective emergency preparedness is essential if cultural institutions and heritage sites are to rapidly respond when facilities and collections are threatened by disasters. It is equally important that institutions and sites look for opportunities to reduce future disaster damages by implementing hazard mitigation measures. How to excise the crisis management theory to handle disaster such as earthquake in China has been an important research focus for scholars and governments at all levels. This paper applied the crisis management theory to analyze the 6.3earthquack in Puer and concludes some advices and experience from the disaster which will be helpful for the same disaster situation in the future.
\end{abstract}

Keywords: Unexpected Natural Disasters, Puer, Earthquake

\section{Introduction}

Since the early 1960s, the crisis management theories for the handling of unexpected emergencies have been an independence subject in western developed countries. The development of crisis management theories has provided strong support for every country to establish relative perfect crisis management system.

Crisis Management is a term often used to describe the way in which an organization or government handles a crisis. A paucity of definitions exists within dictionaries, policy documents, and crisis literature, and where they do exist, those definitions provided differ vastly in focus, scope, and terminology used. In accordance with the traditional definitions, it is suggested that Crisis Management should be comprehensively understood as: the provision of an organizations' or governments' pre-planned, rapid response capability supported by a leadership, information management and communications capacity in an integrated fashion to enable fast decision making at a strategic level within a structured environment, and thereby allowing for effective recovery and protecting an organizations' survival or reputation.

Crisis management is the nature of activities to respond to a major threat to a person, group or organization. Crisis management is a relatively new field of management. Typically, proactive crisis management activities include 
forecasting potential crises and planning how to deal with them, for example, how to recover if your computer system completely fails. Many people would refer to this, instead, as risk management and not crisis management. Hopefully, organizations have time and resources to complete a crisis management plan before they experience a crisis. Crisis management in the face of a current, real crisis includes identifying the real nature of a current crisis, intervening to minimize damage and recovering from the crisis. Crisis management often includes strong focus on public relations to recover any damage to public image and assure stakeholders that recovery is underway.

In China, the research on crisis management, which is in the stage of introduction, adaptation and Preliminary study at present, have begun from the 21st century. Generally, the public crisis are always led by some unexpected incidents. The term of unexpected incident refers to the natural disasters, incident disasters, event of public health and social safety incidents which break out unexpectedly and will cause serious social damage possibly. While the governmental emergency management means that the government will carry out the organized, planned and constant management activities to handle all kinds of unexpected incidents through establishing perfect emergency management system with the aim of preventing and handling unexpected incidents effectively, ensuring public safety and promoting the coordinated and stable development of social economy.

The most important difference among different countries lies not in the forms of governmental rule, but in the high or low level of governmental rule. The high or low level of governmental rule actually refers to the government's ability to govern country which is the important part of modern government construction. The report on the 17th National Congress of the CPC puts forward that the emergency management system for unexpected incidents should been improved. the Third Plenary Session of the Eleventh Central Committee of the Chinese Communist Party has lay down that the emergency management system in countryside should be established and improved so as to improve the ability to handle crisis incidents. At present, the management system of public crisis in China is mainly relied on local governments which bear the responsibility to handle all kinds of unexpected incidents. So the local governments have played a dominant role during the process of handling unexpected incidents. The result of emergency management not only relates to the construction of government image, but also will influence the fundamental right of citizens.

Based on the case of 6.3 earthquake in Puer, the paper puts forward that the local governments' ability to handle natural disasters should been improved further and the public governance with multi-dimensional social capital should be introduced and integrated within the framework of constitutional government.

\section{The Experience of Earthquake Relief from the 6.3 Earthquake}

On 3rd of June, 2007, the region of Puer was subject to a 6.4 magnitude earthquake which effected more than forty million people from five counties, eighteen towns, one hundred and eleven villages with a loss of 1034 million Yuan RMB. 
After the earthquake, the government has adopted a series of measures to decrease people's loss and formed some beneficial experience which will be valued for the future management and handle of unexpected incidents.

Firstly, the governmental leaders attached weight to the handle of earthquake and guaranteed the relief at time. After the earthquake, the Yunnan Provincial Committee of the CPC, provincial government and Party committees at all levels in the earthquake-stricken area paid close attention to the relief work and took the disaster relief, production revival and home rebuilding as the central work, which provided strong guarantee for the work of earthquake relief and reconstruction. The Yunnan Provincial Committee of the CPC, provincial government mapped out the plans, went into the disaster areas and ensured every work made successfully. About two thousands of members of working force were assigned to participate in the work of restoration and reconstruction.

Secondly, the Party committees and governments at all levels organized strictly and set up specific measures. The Party committees and governments at all levels set up responsibility system which clears the responsibilities for every leader. According to the principle of fair, just and open, the work of disaster check and disaster assessment were implemented rapidly and the overall design and specific measures of restoration and reconstruction were established, which defines the guiding principles, basic principles, objects and tasks, allowance policies, executive method and guarantee measures as well as some policies such as deductible expenses, Discount loans and so on. At the same time, according to the principle of scientific concept of development, new horizons and new thoughts, the Puer Municipal Committee and municipal government integrated the restoration and reconstruction into the Construction of a New Socialism Rural Area, industrial development, urban planning, shock-proofing relying on the huge support and assistance from nation and Yunnan provincial government. The restoration programs also were implemented successfully through employing excellent and professional project management corporation, professionals, and work teams so as to guarantee effectively the quality of restoration projects. In order to implement strictly the regulation of the funds for disaster relief, the Puer Municipal Committee and municipal government established some relative advices and notices, which guarantee the correct use of the funds for disaster relief.

Thirdly, the Puer Municipal Committee and municipal government always put the work of restoration and reconstruction at the first place, earnestly implement the policies of the Yunnan Provincial Committee of the CPC, provincial government and focused on the work of disaster relief by closely placing stress on the realization of Two Goals. In the beginning of restoration and reconstruction, a work team was made up of 34 municipal leaders who respectively shoulder responsibility 77 departments and units and guide the work of restoration and reconstruction.. That arrangement had effectively promote the work of restoration and reconstruction in Puer disaster region.

Fourthly, the Yunnan Provincial Committee of the CPC and the Puer Municipal Committee and municipal government paid attention to the correct publicity supervision and guidance during the work of disaster relief. Based on the 
engendering the news bulletin and statistical newsletter about the restoration and reconstruction, the governments formulated news and information plan at time, intensified External propaganda work and made the relevant information be public in society in an appropriate manner such as interview in disaster areas, contributions and press conferences. These measures met the needs of the public to learn more about the restoration and reconstruction in the disaster areas. At the same time, with the aid of Special Report about the restoration and reconstruction from the new media such as CCTV, the Puer Municipal Committee and municipal government transmitted the care and concern from the Party Central Committee and the State Council, the Yunnan Provincial Committee of the CPC, provincial government and Party committees at all levels to our cadres and masses in the disaster areas. Meanwhile, the important commends from the Party Central Committee and the State Council, the positive measures and the achievement made in the disaster relief also were propagandized and reported in time.

\section{The Approach to Improve the Ability to Handle Unexpected Incidents}

The natural disaster is a kind of unexpected public incidents with the high frequency in the world, so the governments at all levels should constantly rethink what they have done in the past, look to the future, review their experience, draw the lessons from disasters and seriously address the problems they are faced with. More importantly, the crisis management system should be established and improved further so as to strengthen the governments' ability to respond and governance level. The governments' ability to respond for unexpected incidents should be an important step and basic goal for the construction of governmental ability of governance and the Construction of Harmonious Society. Although each disaster has its own characteristics and it also need to adopt different ways to handle, the governments at all levels should pay more attention to the following aspects during the handle of natural disasters.

\subsection{Insisting the values of preventing huge disasters and implementing disaster relief}

In recent years, more and more extreme climate events and earthquake disasters had taken place in China frequently, so the leaders at all levels should have the mind to handle the huge disaster, strengthen training, education and crisis awareness. The emergency preplan, the learning, training and drill for the preplan should be straightened so as to promote the implementation of disaster relief effectively and successfully. Some legal system also is set up in China, but it is not effective to be implemented when the disasters is coming. Thus, the governments at all levels should strengthen the guidance, supervision and inspection on emergency preplan in some basic units such as communities, factories and mines, schools and countryside and so on.

\subsection{Strengthening the legislation construction on unexpected incidents}

At present, the lawmaking orientation has some problems in China. One hand, the relating laws have not established a set of detailed rules which have influence the implementing effects. On the other hand, the existing laws are not made very clear about legal liability of handling unexpected incidents and the phenomena that government policies 
and executive orders often replace the legal functions is inevitable in real situation. Finally, the establishment of some laws and regulations lack of legal basis which will result in the lack of necessary legal guarantee for many crisis management activities. So ,the governments at all levels should set up some clear laws and regulations about crisis management according to the principle of practical application.

\subsection{Insisting the principle of the} governmental guiding, decentralized management, social interaction and self-help

The present crisis management system with the characteristics of generalization has evolved from the military guard. The comprehensive coordinated organization for crisis management established by governments at all levels is not perfect and has single function. From the perspective of whole society, the alert system and crisis management should be improved further including the cooperation, information share, professional handle and the organization of relief team. At the same time, it is impossible to realize effective relief if there is no the participation of social forces in an open and decentralized society. The participation of social forces not only can relieve the negative impact of crisis among the people, but also make the people learn more truth about crisis so as to decrease afraid and rumors which is resulted from crisis or unexpected incidents. So the participation of social forces can play a role of maintaining social stability and restoring social order. Due to the participation of social forces, the information about crisis can be learned by most people, the credibility and possibility of governmental policies can be improved and the cost of policy establishment and implementation can also be decreased.

\subsection{Persisting in the Theory of "People Oriented" to implement disaster relief}

Any disaster relief should be implemented through ensuring victims' Safety of Life and the basic survival needs. From the perspective of society, the governments at all levels should establish a series of policies to make society stable and mobilize social forces to participate in crisis governance. For society, the hugest damage which will be brought by social crisis is the damage to the normal social damage and the frangibility of social mentality. So the most important things is to maintain stable social order while the disaster is coming. The governments at all levels should firstly ensure the normal social public live so as to avoid the bigger psychological harm which result from disasters for people. At the same time, the governmental image should also be maintain during the handle of public crisis through opening information about disaster. Except governments, the media is the major channel to provide all kinds of information for the people. Sometimes, the people will believe the media more governments, so the media can be decrease many incorrect information which will results in social unrest.

\section{Conclusions}

Crises are frequent and varied, and may have profound effects on individuals and organizations. disasters such as earthquakes attacks threaten people' $s$ lives. Without doubt, crisis Management is a key capability in the armory of organizations' or governments' resilience to disruption. It is the strategic capability in times when fast, effective response is required, when information may be 
sparse or contradictory, reputation or lives may be at stake, and multi-faceted leadership is required to provide strategic vision and direction. Crisis Management is an executive responsibility and capability which is enhanced by structure, plans, procedures, and training, to allow a coherent and effective response to delivered in times of need, and, ultimately, for an organization to transition back to normality in the most efficient way possible. It is delivered by various processes to provide a capability of response at an appropriate level, and allows an organization and its staff to be confident in their ability to react to any eventuality in a coherent manner in order to direct the on - going delivery of the business or services and management of the impacts of a disruption from a strategic perspective.

Whether or not any government manage and handle the crisis effectively, maintain normal social order and ensure the safety of the lives and property of the people will be an important sign for governments to win the people's confidence and a touchstone for government to be responsible to the people. In order to strengthen the sense of responsibility, calling and suffering consciousness, the governments at all levels should place earnestly the crisis management system in the first place and establish and perfect the crisis management system to handle the unexpected public incidents.

\section{References}

[1] Compiling Team for Basic knowledge about the handle of unexpected incidents. Basic Knowledge about the Handle of Unexpected Incidents [M]. XinHua press, 2008:7.
[2] Gao Xiaopin, Liu Yihong. Reviews on the Emergency Management Research in China [M]. Chinese Public Administration, 2009(9):9.

[3] Shi Yungui. The Ability of Chinese Government to Handle Public Crisis: taking WenChuan Earthquake as Research Background [J]. Social Science Research, 2009(3):16 22.

[4] Liu Xia, Yan Xiao. The Construction of "One Case and Three Systems" of Crisis Management in China: Challenges and Reconstruction [J]. Journal of Political Science, 2011(1):94 100.

[5] Wang Hongwei, Dong Keyong. The Model Transformation of social mobilization of Emergency: from Command Model to Governance Model [J]. Journal of Chinese Academy Of Governance, 2011(5):22 26.

[6] Ma Guofang, Na Chanhui. The Crisis Relief of Local Governments from the Perspective of Natural Disasters in Yunnan [J]. Journal of Yunnan Nationalities University (Social Sciences), 2006(9):76 78. 